\title{
Evaluation of Drug Pricing in Nigeria: A Focus on Affordability and Availability of Essential Medicines in Federal Capital Territory Abuja
}

\author{
Abubakar Mustapha Danraka* Akpan Aniekan Edet Shingin Kovona Musa Sunday Ndiana-Abasi Ime \\ National Institute for Pharmaceutical Research and Development, (NIPRD) Idu, Abuja, Nigeria
}

\begin{abstract}
Critical to the success of a country's healthcare delivery services is the affordability, availability, and accessibility of essential medicines to the populace irrespective of their income status. The price of medicines is an important determinant of medicines affordability and accessibility. Due to seeming inefficient health insurance programs, medicine financing in Nigeria is generally out-of-pocket. In Nigeria, drug prices are set mostly by market forces, with government tariffs, taxes, and distribution mark-ups accounting for a significant proportion of the final price. The following thematic areas of interest to were the focus in evaluating the current situation of drug pricing: National Drug Policy and Drug Pricing; National Drug Distribution Guideline and Drug Pricing; National Policy Framework on Drug Revolving Fund and Drug Pricing; Nigerian Pharmaceutical Market and Drug Pricing. The study evaluated drug pricing in Nigeria by comparing the availability and prices of various brands of a chosen set of essential medicines in different parts of the health sector and different types of health facilities in the Federal Capital Territory Abuja to assess the availability and affordability of these medicines. The study design used a questionnaire format data collection tool based on the 2nd edition of the World Health Organization (WHO) and Health Action International manual for measuring medicine prices, availability, affordability, and price components. The survey was carried out within the Federal Capital Territory Abuja at both public and private health facilities, including community pharmacies. A total of 145 facilities were enumerated and $20 \%$ were successfully surveyed. Key data collected included; percentage availability, price of originator brand and generics, price ratio to the international reference price, and the economic effect of current drug prices on the populace.The results showed varied and fantastic outcome, on inferential statistics in comparative analysis; Firstly, for the Public hospital vs Private hospital Medicines' Prices, there was a significant difference $(\mathrm{P}<0.05)$ between the price of medicines in private hospital and the median price of medicines in public hospitals. Also, price of medicines in private hospital was 2.9 times higher than the median price of medicine in public hospital ( $\mathrm{p}=0.013, \mathrm{t}=2.9$ ); Secondly, for the Innovator brand vs Most sold generic brand in community pharmacy, there was a significant difference between the median price of innovator brands of medicines and the median price of the most sold generics. The median price of the innovator brands was approximately 5 times the median price of the most sold generics $(p=0.000291, t=4.689)$; Thirdly, for the Price of medicines across community pharmacies (innovator brand), there was no significant difference $(p>0.05)$ in the prices of innovator brands across the community pharmacies assessed. $(p=0.459)$; Fourthly, for the Price of medicines across community pharmacies (Most sold generic), there was no significant difference $(p>0.05)$ in the prices of the most sold generic brands of medicines across community pharmacies assessed ( $\mathrm{P}=0.915)$; Fifthly, for the Price of medicine across public hospitals, there was no significant difference $(\mathrm{p}>0.05)$ between the prices of medicines across the public hospitals assessed. $(\mathrm{p}=0.877)$. There exists a huge price disparity between public and private health facilities, hence there is an overarching need to regulate drug prices in the health sector so as to ensure affordability and availability of essential medicines and other healthcare commodities. There is poor availability of some essential medicines particularly in the public health pharmacies, it is imperative that appropriate measures be put in place to ensure medicine availability. Improving access to medicines is key to attainment of Universal Health Coverage and Patients' satisfaction of the healthcare delivery system.
\end{abstract}

Keywords: Drug Pricing, Essential Medicines, Affordability, Availability, Nigeria, FCT Abuja

DOI: $10.7176 / \mathrm{JHMN} / 97-01$

Publication date: January $31^{\text {st }} 2022$

\subsection{INTRODUCTION AND LITERATURE REVIEW}

Critical to the success of a country's healthcare delivery services is the affordability, availability, and accessibility of essential medicines to the populace irrespective of their income status (Bansal and Purohit, 2013). The price of medicines is an important determinant of medicines affordability and accessibility (WHO, 2015). About $20-60 \%$ of health spending in low- and middle-income countries is on medicines (Cameron et al., 2009). Due to inefficient health insurance programs, medicine financing in Nigeria is generally out-of-pocket. However, as of 2018, according to World Bank data, almost half of the population are living below the international poverty line of 2 USD per day (FMOH/WHO, 2006; World Bank, 2018). This has resulted in medicines, particularly those with higher costs to be unaffordable for a large section of the population. Therefore, issues 
concerning the prices of medicines should be paid attention to, as it plays a key role in improving access to essential medicines in Nigeria.

In Nigeria, drug prices are set mostly by market forces, with government tariffs, taxes, and distribution mark-ups accounting for a significant proportion of the final price (UNIDO, 2011). Pricing of medicines is not regulated and prices are not part of market authorization/registration (FMOH/WHO, 2006). Key findings in a national survey on medicine prices undertaken in 2006 by the Federal Ministry of Health in collaboration with the World Health Organization and Health Action International included the following: wide variability of prices of the same medicines between facilities, sectors and different types of the same product; innovator brands cost between 2 - 7 times the lowest-priced generic equivalents; patients pay between 2 to 64 times international reference prices for medicines in various facilities in the public and private sectors of Nigeria; private health clinics were shown to charge up to $184 \%$ more than the public health facilities and $193 \%$ more than private retail pharmacies (FMOH/WHO, 2006). The impact of a lack of pricing control is being passed consumers through higher medicine prices (UNIDO, 2011).

The National Drug Policy in Nigeria first launched in 1990 and revised twice in 2005 and 2021, with aims to provide the Nigerian population with adequate supplies of medicines that are effective, affordable, safe, and of good quality, ensuring the rational use of such medicines and promoting increased local production of essential medicines does not have any legal or regulatory provisions affecting the pricing of medicines (Ogbonna et al., 2015). Therefore, there is a need for a drug pricing policy that aims to reduce the high prices and wide disparity between prices of medicines.

To assist national policymakers and other stakeholders in identifying and implementing policies to manage pharmaceutical prices, WHO in 2015 developed a guideline highlighting policies with potential in pharmaceutical price management. The policy intervention areas highlighted in this guideline included; regulation of mark-ups in the pharmaceutical supply and distribution chain, tax exemptions/reductions for pharmaceutical products, application of cost-plus pricing formulae for pharmaceutical price setting, use of external reference pricing, promotion of the use of generic medicines and health technology assessment (HTA) as a tool to support reimbursement decision-making as well as price-setting/negotiation. According to WHO, (2015), in as much as these policies have potential benefits, there are also potential downsides associated with them and should be taken into consideration by policymakers. For instance, considering the regulation of markups in the pharmaceutical supply and distribution chain, this can have unintended negative consequences on availability and access through distortion of prices. Tax exemptions/reductions for pharmaceutical products can lead to loss of revenue for national governments which may harm some aspects of the health care system. As regards the application of cost-plus pricing formulae for pharmaceutical price-setting formulae used by countries to calculate cost-plus prices can be manipulated to the advantage of manufacturers and the disadvantage of patients. As regards the use of external reference pricing, the choice of countries as reference countries may lead to inflated prices.

The selection and implementation of policies to manage the price of medicines must take account of the wider health and pharmaceutical structures within which a country operates. To achieve an efficient price regulation, WHO recommends a combination of different pharmaceutical pricing policies based on the objective, context, and health system of the country involved (WHO, 2015) In Nigeria, the pharmaceutical and health sector is complex and has various actors who have benefited from its disorganized nature for decades, therefore carefully analyses are needed before a policy option is implemented (FMOH/WHO, 2006). Therefore, it will be rational to look at the price regulation methods that have worked in similar developing countries. Some case studies are highlighted below.

South Africa in 2004 introduced transparent drug pricing mechanisms, including a Single Exit Price (SEP). The SEP sets a price at which a prescription drug maker must sell to all pharmacies. Studies have shown that the SEP had an immediate effect on the price of medicines in South Africa, with a $22 \%$ reduction in prescription medicine prices in the first year after its introduction. But there remains a dearth of data on the long-term effectiveness of transparent pricing in the country (WHO/HAI, 2011).

In India, Drugs Price Control Order (DPCO) in 1979 specified 348 medicines under price control. The number of medicines was reduced to 74 in 1995. The policy review indicates that between 1996 and 2006 the rise in prices of all medicines was $39.93 \%$ and for price-controlled medicines was $0.02 \%$ (WHO/HAI, 2011). However, as of 2013, the National Pharmaceutical Pricing Authority (NPPA) in India, authorized by the ministry of chemical and fertilizers (Department of pharmaceuticals), regulated the pricing of all the drugs included in the National List of Essential Medicines (NLEM), as a result, the prices of all the 348 essential medicines originally included in 1979 were reduced and made available at a low cost. Almost a year later another amendment was made in DPCO, which authorized NPPA to control prices of other 108 life-saving drugs which were not originally included in NLEM (Ahmad et al., 2015). The price of bulk drugs is fixed by specifying a maximum rate of return to bulk drug manufacturers. The maximum retail prices are fixed using cost-plus methods and are determined by the use of data submitted by companies and by comparing elements of cost of each company. 
India also uses generic competition as a means of regulating drug prices (Narayan, 2007)

In China, Maximum retail prices are set by the National Development and Reform Commission. Prices are set based on declared costs submitted by manufacturers and are calculated as factory prices with duty/taxes and retail distribution profits incorporated however, the prices submitted by manufacturers are not checked for accuracy (WHO/HAI, 2011) Also, the National Development and Reform Committee has traditionally set medicine pricing policy and has final approval on the national product price list, while provincial committees compile a list of reimbursable products for different regions (Mossialos et al., 2016). Hospitals, meanwhile, purchase drugs directly from wholesalers and use expert councils to evaluate the safety, efficacy, and costeffectiveness of drugs before buying them through tender processes (Sun et al., 2008).

\subsection{THEMATIC AREAS}

Having seen countries with clear examples of drug price regulations such as China, India, South Africa, Nigeria is also not exempted. There are existing policies that were designed to address drug pricing, the purpose of this study was to highlight the current reality with regards essential medicines affordability and availability across private and public health facilities. The study focused around the following thematic areas of interest to evaluate the current situation of drug pricing.

\subsection{National Drug Policy and Drug Pricing}

Good quality medicines that are affordable and accessible are essential for the improvement of the quality of life of a population. The important role of national drug policies in making sure that medicines are available and are of good quality has been recognized by the World Health Organization and Governments. The World Health Assembly in 1975, in their resolution WHA 28.66, requested WHO to offer support to countries formulating national drug policies, and create strategies to ensure that good quality medicines are accessed and rationally used (Taylor, 2012).

The maiden National Drug policy (NDP) for Nigeria was launched in 1990 to solve the challenges associated with inadequacies of drug supply and distribution (NDP, 2005). The NDP was revised in 2005 and the latest edition which is the 3rd has been launched by the Federal Ministry of Health in September 2021. Drug prices in Nigeria are set predominantly by market forces, with government tariffs, taxes, and distribution markups accounting for a significant proportion of the final price (UNIDO, 2011).

The NDP takes into account the variation in drug prices between the public health institutions and the private retail pharmacies, with the drug costing more in the public health institutions, and also the drug prices varying between one facility and the other (NDP, 2005). However, the NDP has failed to propose a strategy for addressing the problem of price variation in Nigeria, even though the problem has been identified.

\subsection{National Drug Distribution Guideline and Drug Pricing}

A good distribution system is essential for drugs to reach the final consumer, the patient. The National Drug Distribution Guideline (NDDG) was published in 2012 to, provide a guide for the distribution of drugs in Nigeria (Onyebuchi, 2015).

The Nigerian distribution system is fragmented and inefficient, which has resulted in a surge of fake, substandard and adulterated products finding their way into the market as a result of the activities of fraudulent individuals (Ojo, 2017). The guideline is formulated to allow three key modes of drug entry into the country, from the manufacturers and importers, these include; the mega drug distribution centers, the state drug distribution centers and, the national health program, and the listed channels will interact with the wholesalers, who will, in turn, interact with community pharmacies, private health practitioners, public and primary healthcare facilities, and then to the final consumer (Ogbonna et al., 2015).

With respect to drug pricing, the NDDG directs that the permissible mark-up for costing of drugs and health commodities shall be determined by market forces (NDDG, 2012). This has left the market vulnerable to manipulations by various agents and can be attributed to being the cause of the exorbitant drug prices.

\subsection{National Policy Framework on Drug Revolving Fund and Drug Pricing}

Drug Revolving Fund (DRF) is a system in which the revenue that is gotten from drug sale to patients is used in the procurement of new drugs, to ensure availability and an effective and efficient system (Umenai and Narula, 1999). The DRF mechanism within the Bamako Initiative was adopted as the initial approach for sustainable financing of drug supply locally in 1988 and with support both technically and financially from donor and support agencies such as WHO, United Nations Children's Fund, and the United Kingdom Departments of International Development (DFID) (Ogbonna and Nwako, 2016). The DRF comes into play in situations involving low funding which could hurt access to essential medicines, thus it can make supplementary resources available to make low-cost essential medicines accessed easily (Uzochukwu et al., 2002). The DRF is associated with a substantial amount of revenue generation, which is added to the central allocations for improved service 
and sustainability of the scheme (Ogbonna and Nwako, 2016).

There no clear structural framework in the Nigerian National Policy Framework on DRF (1994) to regulate drug pricing both at the Central Medical Store (CMS) and zonal warehouses as well as for retail pricing at the individual health institutions levels. It only takes into consideration Federal Health Institutions (FHIs), and prices are to be determined by market forces and also at the discretion of the FHIs.

\subsection{Nigerian Pharmaceutical Market and Drug Pricing}

Nigeria has a large market for drugs, with over 150 existing pharmaceutical companies, but despite the large number, only about 82 are active (Erhun et al., 2005). With the country's production capacity being less than 30 percent, a good portion of the drugs used are imported (Okoli, 2000), and a bulk of the imports coming from Asia (Akinyandenu, 2013).

Different estimates have been made regarding the size of the Nigerian pharmaceutical market. The Pharmaceutical Manufacturing Group of the Manufacturers Association of Nigeria (PMG-MAN) in 2009, estimated the size of the total healthcare and pharmaceutical market to be over US\$ 2 billion annually. The estimated market for prescription ethical pharmaceuticals is about US\$ 500 million, and for the over-the-counter (OTC) medications to be around US\$ 900 million (UNIDO, 2011). PMG-MAN also estimates the Nigerian market for biological products such as vaccines, insulin, interferon, etc. to be worth about US\$100 million, in addition, other associated healthcare and lifestyle products account for about US\$ 500 million. Nigeria is also estimated to supply 60 percent of the health products that are consumed in the Economic Community of West African States (ECOWAS) sub region by volume (PMG-MAN, 2010); with an approximate population of 600 million, the sub-region represents a huge potential market.

Drug prices in the Nigerian market are set mostly by market forces, with the government tariffs, taxes and distribution mark-ups accounting a significant proportion of the final price (UNIDO, 2011). According to a study by Federal Ministry of Health in collaboration with the World Health Organization and Health Action in 2006, patients paid between 2-64 times the international reference prices for medicines in both the private and public sectors. Innovator brands cost between 2-7 times the lowest-priced generic equivalents, prices in the public sector were almost similar to those in private pharmacies, and private health facilities charged about 184 percent more than the public health institutions, and about 193 percent more than the private retail pharmacies (FMOH/WHO, 2006).

The PMG-MAN as the umbrella association of Pharmaceutical Manufacturing companies in Nigeria have not made published and made public any formal document that guides its members on regulating retail and wholesale prices of medicines to be in use in the open market.

\subsection{Objectives of the Study}

The study evaluated drug pricing in Nigeria by comparing the availability and prices of various brands of a chosen set of essential medicines in different parts of the health sector and different types of health facilities in Abuja metropolis to assess the availability and affordability of these medicines. The information generated in the study, would encourage the exploration of appropriate policies that would help in improving access and affordability of medicines to Nigerians, promote patients' satisfaction in utilization of healthcare delivery system and ultimately improve Universal Health Coverage.

\subsection{METHODOLOGY}

\subsection{Study design}

The questionnaire format is based on the 2nd edition of the World Health Organization (WHO) and Health Action International manual for measuring medicine prices, availability, affordability, and price components. The survey was carried out within the Federal Capital Territory Abuja at both public and private health facilities, including community pharmacies. A total of 145 facilities were enumerated and $20 \%$ were successfully surveyed. Key data gathered from the field included; percentage availability, price of originator brand and generics, price ratio to the international reference price, and the economic effect of current drug prices on the populace.

\subsection{RESULTS}

A. Descriptive statistics

1. Medicine Availability across Community Pharmacies

Inclusion Criteria: Availability of at least one brand of a drug in each pharmacy 


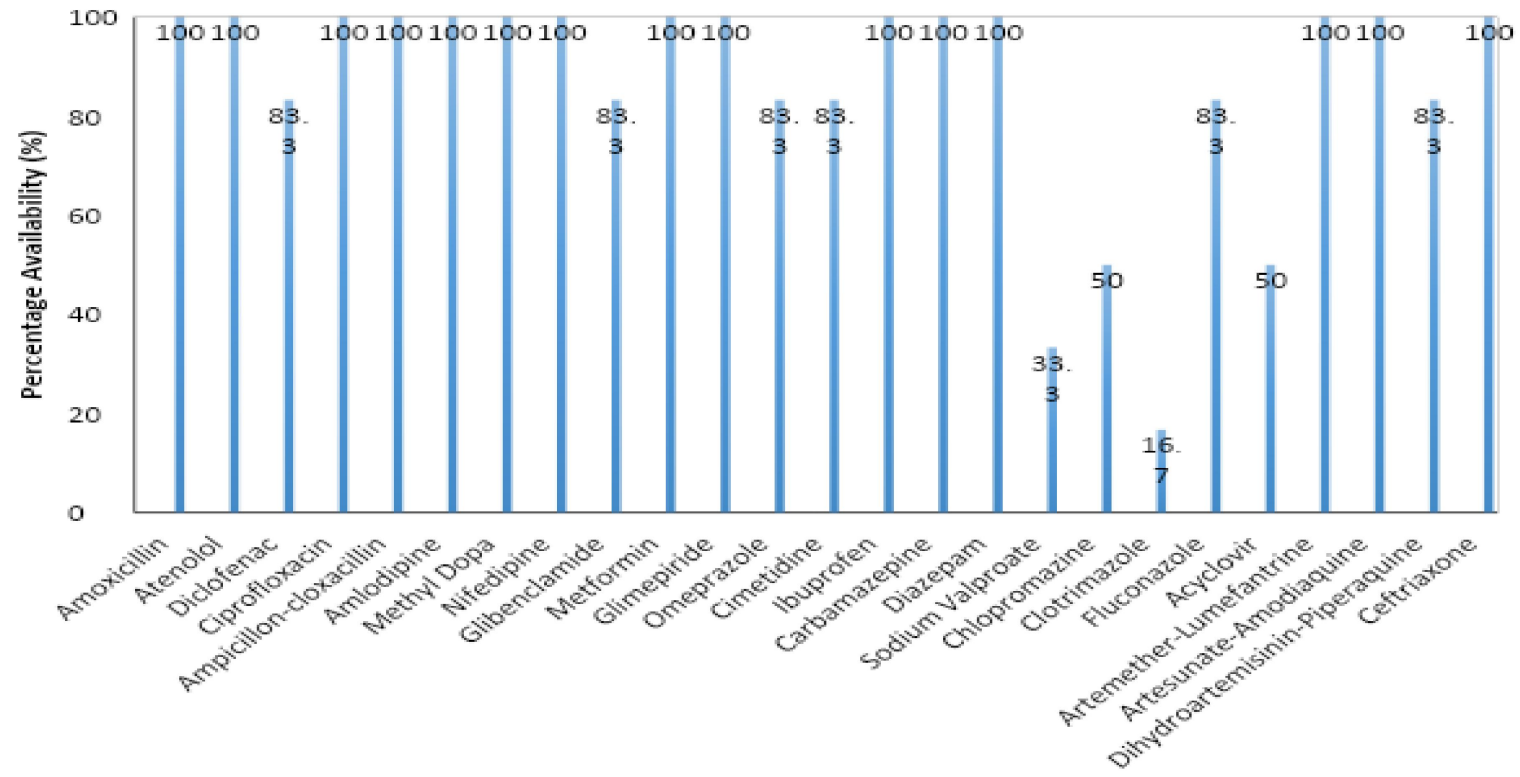

Figure 1:Medicine Availability across Community Pharmacies

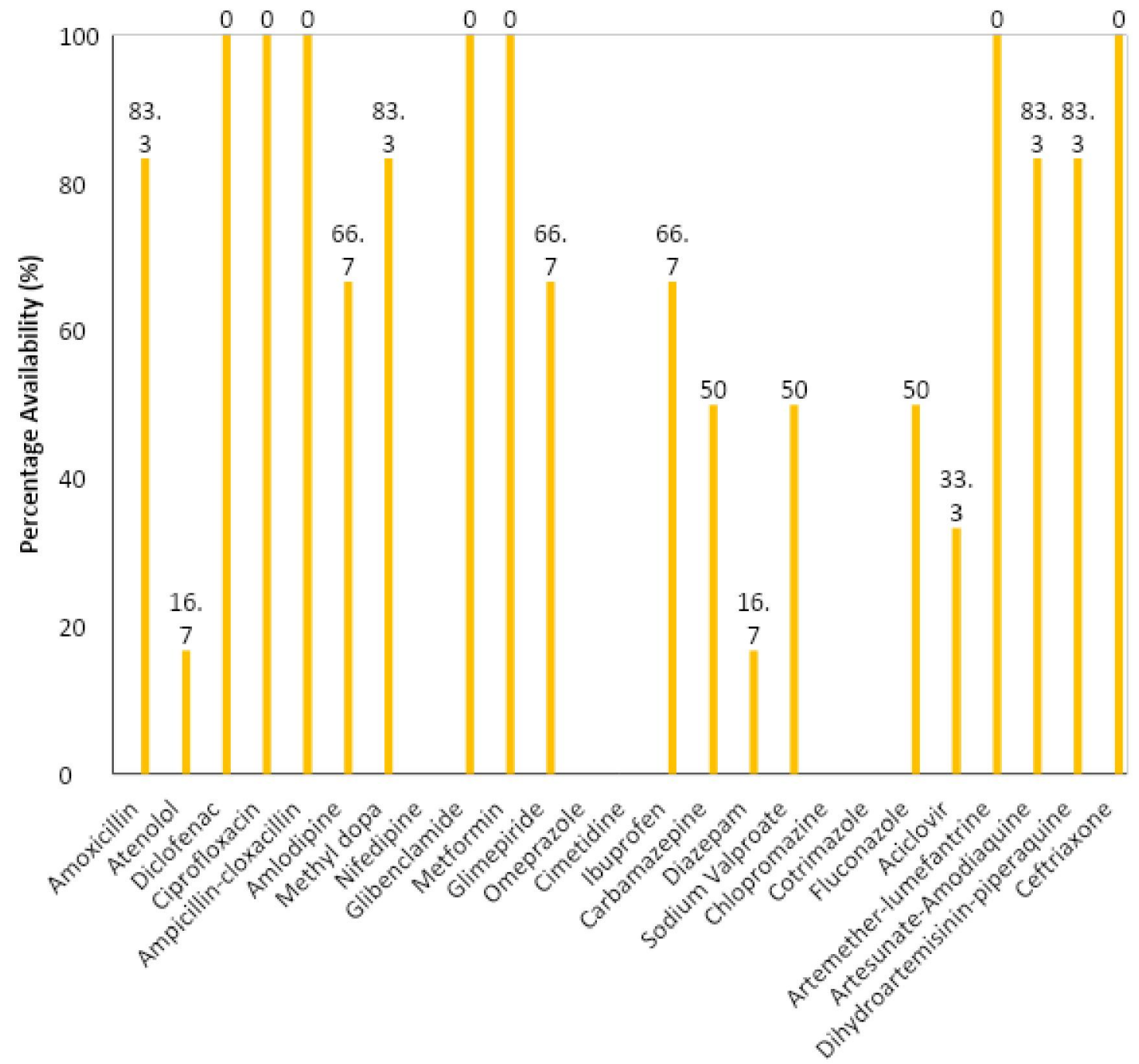

Figure 2: Availability of innovator brands across community pharmacies 


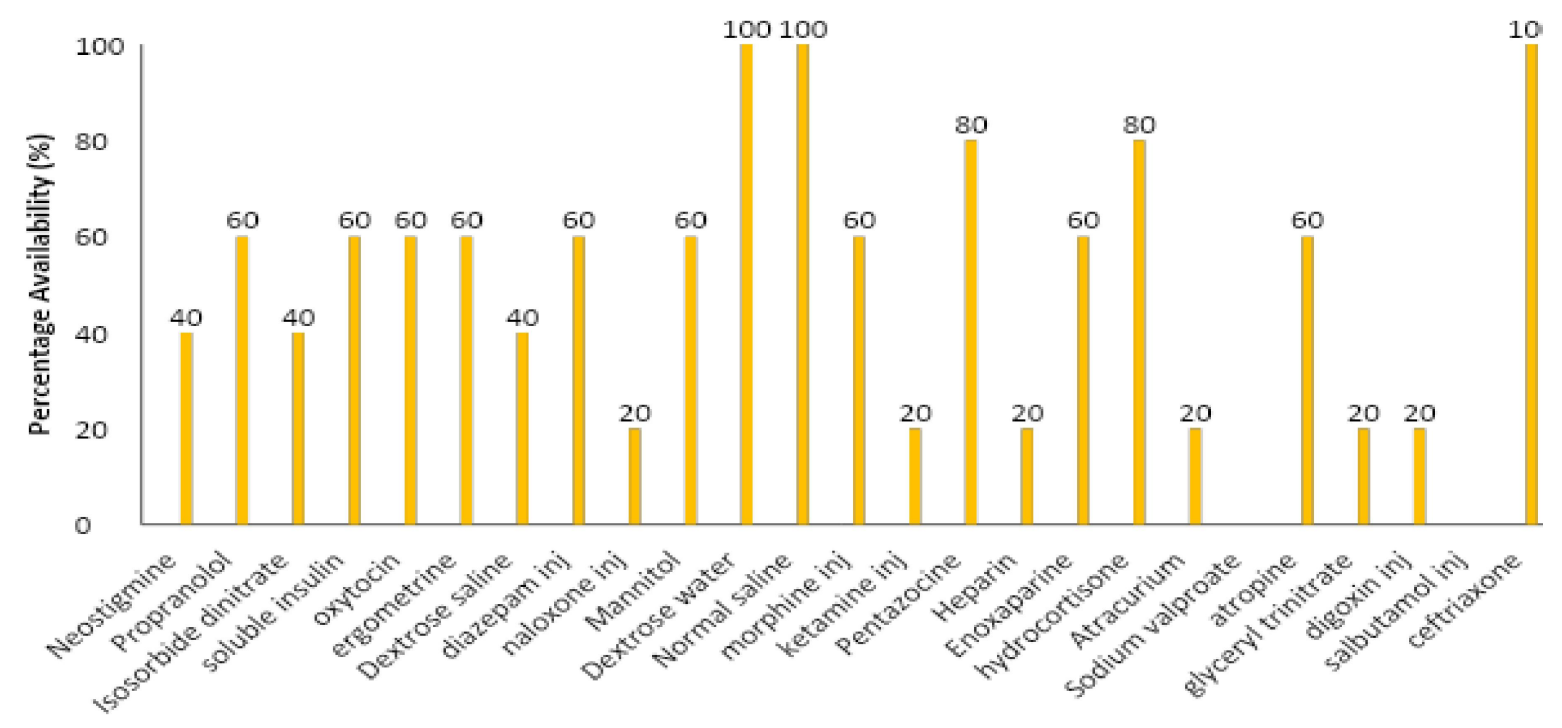

Figure 3: Medicine Availability across Public Hospital

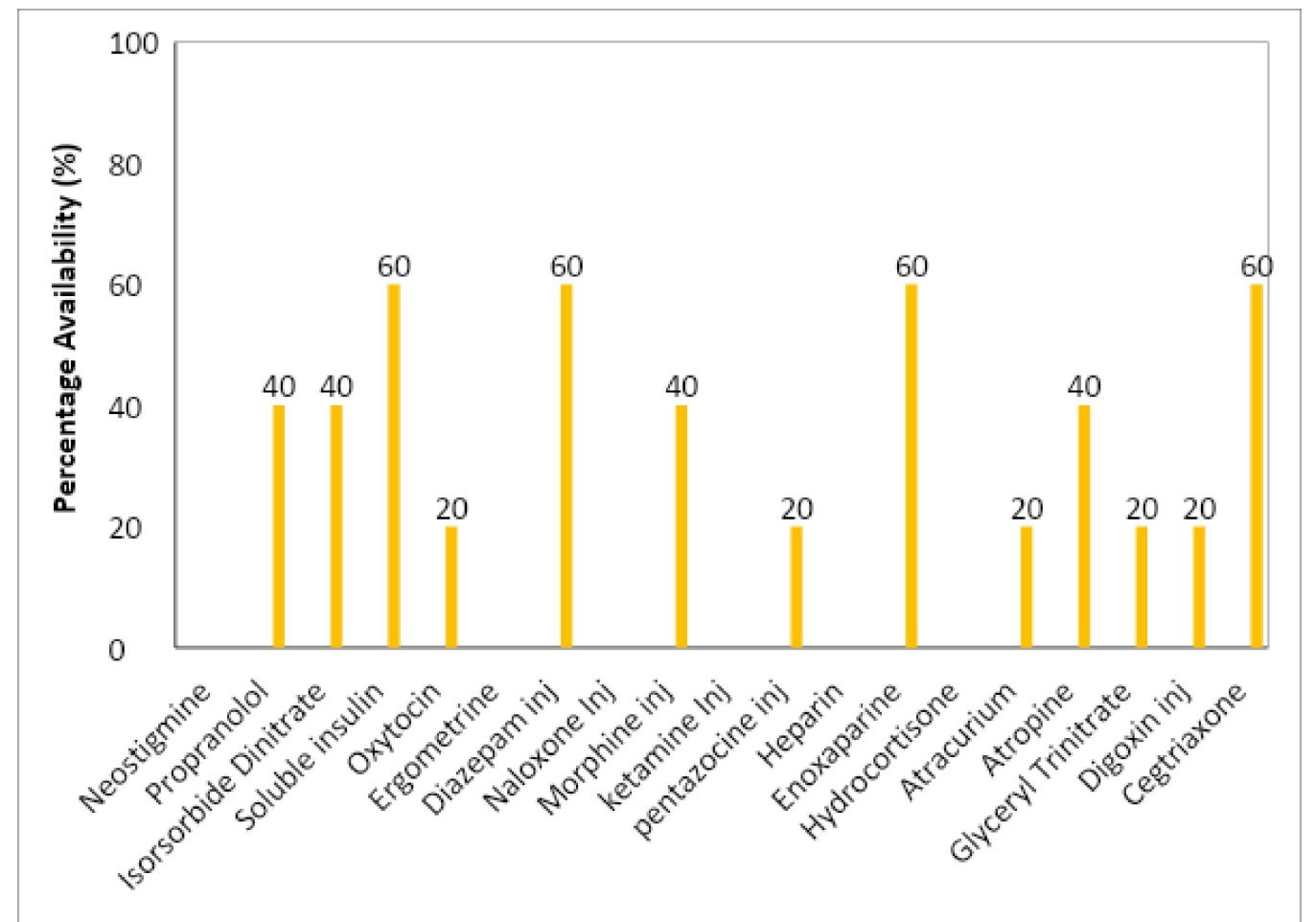

Figure 4: Availability of innovator brands across public hospitals

B. Inferential Statistics: Comparative analysis

1. Public hospital vs Private hospital Prices

There was a significant difference $(\mathrm{P}<0.05)$ between the price of medicines in private hospital and the median price of medicines in public hospitals. Also, price of medicines in private hospital was 2.9 times higher than the median price of medicine in public hospital $(\mathrm{p}=0.013, \mathrm{t}=2.9)$

2. Innovator brand vs Most sold generic brand in community pharmacy

There was a significant difference between the median price of innovator brands of medicines and the median price of the most sold generics. The median price of the innovator brands was approximately 5 times the median price of the most sold generics $(p=0.000291, t=4.689)$.

3. Price of medicines across community pharmacies (innovator brand)

There was no significant difference $(\mathrm{p}>0.05)$ in the prices of innovator brands across the community 
pharmacies assessed. $(\mathrm{p}=0.459)$

\section{Price of medicines across community pharmacies (Most sold generic)}

There was no significant difference $(\mathrm{p}>0.05)$ in the prices of the most sold generic brands of medicines across community pharmacies assessed $(\mathrm{P}=0.915)$

\section{Price of medicine across public hospitals}

There was no significant difference $(\mathrm{p}>0.05)$ between the prices of medicines across the public hospitals assessed. $(p=0.877)$

\subsection{DISCUSSION}

This preliminary study was the first of its kind, in our knowledge to evaluate the affordability and availability of essential medicines in the Federal Capital Territory Abuja using a standard and validated methodology. The WHO/HAI recommends the conduct of studies such as this to drive informed policymaking at all levels. The study was all-inclusive as it provided a broad perspective on issues surrounding drug pricing situation Nigeria.

As a pilot study, it revealed the current state of healthcare and it's utilization in Nigeria, particularly with how patients access their medicines. The challenge of unaffordability is a major factor affecting access to medicines in Nigeria. The World Bank report in 2016 states that about 53.5\% of Nigerians live below the poverty line of less than $\$ 1.90$ per day, together with very poor health insurance coverage with about $95 \%$ outof-pocket payments for healthcare, many patients are likely to face overwhelming costs in accessing and adhering to treatment. This is particularly important as there is no direct regulation of drug prices by the Government.

Affordability and Availability of medicines are perceived by patients' caregivers as the most important indicators in rating their satisfaction for healthcare system utilization. Danraka, (2021) stressed that this foremost realization by all healthcare professionals that the patients' satisfaction should be taken as the most important interest to be defended by all professionals and staff working in the healthcare sector. This would ensure sustainable and productive healthcare service delivery.

There was a significant difference $(\mathrm{P}<0.05)$ between the price of medicines in private hospital and the median price of medicines in public hospitals. Also, price of medicines in private hospital was 2.9 times higher than the median price of medicine in public hospital $(\mathrm{p}=0.013, \mathrm{t}=2.9)$. There was no significant difference $(p>0.05)$ between the prices of medicines across the public hospitals assessed. $(p=0.877)$. The uniformity of prices across all public health facilities is a reflection of the single-end procurement practices from a single central store. Although there exists no clear structural framework on drug price regulation, it shows an effective pricing system and management by public health facilities in the Abuja metropolis particularly the Federal Capital Territory Administration supervised hospitals.

Prices in private pharmacies are known to be higher than in public hospital pharmacies because public hospitals generally apply lower mark-ups. This baseline pilot study showed that medicine prices remained high and potentially unaffordable in private hospitals. While government seeks to extend insurance coverage, it may also be necessary to regulate prices for a basket of medicines as many patients pay for medicines out-of-pocket so as to ensure financial protection. A regular and more comprehensive prices survey in much the same way as prices are monitored for inflation in the country may be necessary.

A significant difference between the median price of innovator brands of medicines and the median price of the most sold generics was observed. The median price of the innovator brands was approximately 5 times the median price of the most sold generics $(p=0.000291, t=4.689)$. There was no significant difference $(p>0.05)$ in the prices of innovator brands across the community pharmacies assessed $(p=0.459)$. There was no significant difference $(p>0.05)$ in the prices of the most sold generic brands of medicines across community pharmacies assessed $(\mathrm{P}=0.915)$. In a recent study, Okubadejo et al (2018) reports that originator brands where available was consistently higher priced than generics. The evaluation of cardiovascular medicines revealed that originator brands were 1.3 - 10.8 times higher than generic formulations.

A recent study by Onalo et al; (2021) within FCT Abuja showed that tested generic brands of Levofloxacin $500 \mathrm{mg}$ Tablet were found to meet the criteria for chemical and pharmaceutical equivalence in compliance with official requirement. Therefore, indicative that generic substitution is permitted for such brands and improving affordability of this class of anti-infective drugs to low-income Nigerians at the grassroots. It is pertinent that quality-assured generics that meet regulatory standards be promoted to ensure reduction in healthcare costs. Also, generic substitution policies should be strengthened so as to encourage local production of high quality medicines.

The availability of medicines by pharmacy type is shown in Figure 1. The medicines evaluated were grouped into antibiotics, antihypertensives, antimalarials, antidiabetic, antiulcer, NSAIDs, and neuroleptics factoring the practice setting and community demand for the medications. Considering overall availability across all formulations and pharmacy types, no medicine was unavailable in any of the pharmacies surveyed. The most frequently found medicines in any formulation were Amoxicillin, Atenolol, Ampicillin-Cloxacillin, Amlodipine, 
Methyldopa, Nifedipine, Metformin, Glimepiride, Ibuprofen, Carbamazepine, Diazepam, ArtemetherLumefantrine, Artesunate-Amodiaquine, Ceftriaxone at $100 \%$ in all pharmacies surveyed. Diclofenac, Glibenclamide, Omeprazole, Cimetidine, Fluconazole was available in $83.3 \%$ of premises, Chlorpromazine, Acyclovir at 50\%, Sodium Valproate (33.3\%), Clotrimazole $(16.7 \%)$ in community pharmacies respectively. Originator brands were less frequently found compared to generics. The low availability of most formulations in the study locations may also be explained by low demand, as pharmacies may not stock medicines for which there is no demand. These findings highlight the need for improved commercial availability of age-appropriate formulations. Figure 2 shows medicine availability across surveyed health facilities. It is important to note that out of 15 public facilities enumerated, 5 facilities were successfully surveyed, and the prices obtained can be inferentially used for all facilities within the metropolis as drugs are procured from a single-unit central store. The Federal Ministry of Health, other high level Policymakers and regulators at the federal level such as the National Agency of Food and Drug Administration and Control (NAFDAC), National Health Insurance Scheme (NHIS), Federal \& States Health institutions, and stakeholders, should collaborate to enact effective pricing strategies to ensure a uniform distribution of drug prices across facilities, as this would be a good cost effective model to guarantee standard quality of care at all levels.

Drugs unavailability are also observed in international donor funded supervised public health programs. A study by Danraka, et al; (2021) on Stock-out of Antiretroviral drugs at health facilities in FCT Abuja revealed that the frequent stock-outs of antiretroviral that led to reduced access were attributed to the increasing HIV client loads, improper documentation and poor ART commodity quantification as well as inaccurate requisitions from bulk suppliers.

Improving access to medicines through affordability should be a priority not just for governments but also for all stakeholders including WHO, PMG-MAN, research institutions and non-Governmental organizations. To meet the 2030 target for the global reduction in NCDs by $25 \%$, the Nigerian government needs a multi-faceted policy approach. Provision of UHC is key in meeting this target and adequate funding to boost medicines, there is need for a complete health system response, including training of the workforce, dissemination of guidelines, and appropriate leadership and governance to enable the provision of high-quality care at all levels of the healthcare system.

The major strength of this study is the use of standardized WHO/HAI methods. The rigor we undertook to confirm that the medicines were in stock by physically sighting was an additional strength that improves confidence in the data we have presented.

\subsection{Limitations and Recommendations}

As this was designed as a pilot to generate rapid data, study site selection, sampling technique and sample size were based on researchers' knowledge of the metropolis. However, based on the robust survey and inclusion criteria, its recognized that these results obtained from his survey would serve an adequate yardstick for generalization to the whole country.

The views of pharmacists and staff at the surveyed facilities were not systematically gathered. This would have provided more detailed information on reasons for poor availability at these facilities. Another identified limitation was that availability of essential medicines was based only on the stock level on the day of visit to the pharmacy, and the reluctance of some hospital and community pharmacies to grant us authorization to carry out the study in their premises. This greatly hindered the span of data collected for analysis.

Further and extensive survey on determination of drug pricing should be done by the Federal Ministry of Health, National Bureau of Statistics and other public health research institutions so as to generate larger and more representative data for the entire country.

\subsection{Conclusion}

There exists a huge price disparity between public and private health facilities, hence there is an overarching need to regulate drug prices in the health sector so as to ensure affordability and availability of essential medicines and other healthcare commodities. There is poor availability of some essential medicines particularly in the public health pharmacies. It is imperative that appropriate measures be put in place to ensure medicine availability. Improving access to medicines is key to attainment of Universal Health Coverage and guaranteeing patients' satisfaction. The concern for medicines' affordability and availability should be of utmost public health priority to all stakeholders in the health industry, so that all identified gaps in the distribution and sales are closed to guarantee accessibility of quality and cheap products to Nigerians at all levels of the society especially the grassroots.

The political commitment to ensure adequate funding in the face of other competing health needs from other NCDs and communicable diseases should be taken up by top government officials in the Federal Ministry of Health and Agencies under the Federal Ministry of Health. There is the overarching need for a multi-sectoral intervention that could be addressed through the development of partnerships among stakeholders and use of 
multiple approaches such as enhancement of local production of these medicines, and provision of subsidies and reimbursement for purchase.

Conflict of interest statement. None declared.

Acknowledgement: The health professionals particularly pharmacists at both public and private pharmacies surveyed that cooperated in giving access to their holding stock of pharmaceuticals are greatly appreciated. Ethical Approval for the study was obtained from the Federal Capital Territory Administration Health Research Ethics Committee.

\section{REFERENCES}

Ahmad A, Khan MU and Patel I. (2015). Drug Pricing Policies in One of the Largest Drug Manufacturing Nations in the World: Are Affordability and Access a Cause for Concern? J Res Pharm Pract. 4(1): 1-3.

Akinyandenu Olusegun (2013). Counterfeit Drugs in Nigeria: A threat to Public Health. African Journal of Pharmacy and Pharmacology 7 (36):2571-2576

Bansal D. and Purohit V. (2013). Accessibility and Use of Essential Medicines in Healthcare: Current Progress in India. Journal of Pharmacology and Pharmacotherapeutics. 4(1):13-18.

Cameron A, Ewen M, Ross-Degnan D, Ball D, Laing R. (2009). Medicine Prices, Availability, and Affordability in 36 Developing and Middle-Income Countries: a Secondary Analysis. Lancet. 373(9659):240-9.

Danraka AM, Iwu WI and Onavbavba G (2021). Stock-Out of Antiretroviral Drugs: A Cross Sectional Study in Selected Health Facilities in Federal Capital Territory, Nigeria. International Journal of Science Academic Research Vol. 02, Issue 04, pp.1267-1271, April, 2021 Available online at http://www.scienceijsar.com ISSN: 2582-6425.

Danraka, A.M (2021). The Impact of Industrial Disharmony amongst Healthcare Professionals in Nigerian Healthcare Sector. Sch J Med Case Rep, Sept 9(9): 880-883. DOI: 10.36347/sjmcr.2021.v09i09.014 ISSN 2347-9507 (Print) | ISSN 2347-6559 (Online) Journal homepage: https://saspublishers.com

Erhun O Wilson, Demehin I Adeolu, Erhun O Mercy (2005) The Impact of Global Pharmaceutical Mergers and Acquisitions on the Nigerian Pharmaceutical Industry. Journal of Medical Marketing. 5(4): 370-382 DOI:10.10571/Palgrave.jmm.5040256

Federal Ministry of Health, Abuja (2004). National Drug Policy. First Revision 2004, in collaboration with WHO, DFID, European Union

Federal Ministry of Health, Abuja/WHO (2006). Medicine Prices in Nigeria.

Federal Ministry of Health, Abuja (2012). National Drug Distribution Guidelines Second Edition

Mossialos E, Yangfeng G, Hu J and Wang L. (2016). Pharmaceutical policy in China: challenges and opportunities for reform. World Health Organization, Geneva.

Narayan S. (2007). Price Controls on Pharmaceutical products in India. ISAS working paper 20.

Ogbonna B. (2016). National Drug Distribution in Nigeria; Implications for the Goals of National Drug Policy. European Journal for Pharmacy and Medical Research . 3: 1-4.

Ogbonna BO, Ilika AL and Nwabueze SA. (2015). National Drug Policy in Nigeria. World Journal of Pharmaceutical Research. 4(6):248-264.

Ogbonna BO, Nwako CN. (2016). Essential Drugs Revolving Fund Scheme in Nigeria; from the Edge of a Precipice Towards Sustainability. Journal of Advances in Medical and Pharmaceutical Sciences, 8(2): 1-8.

Ojo, L. (2017). National Drug Distribution Guidelines and its Benefits. Pharmanews Online. Retrieved from $\mathrm{http} /$ :www.pharmanewsonline.com/nation-drug-distribution-guidelines-and-its-benefits/ on 20/08/2021 $4.12 \mathrm{pm}$.

Okoli Stella (2000). The Pharmaceutical Industry in Nigeria: Historical Review, Problems and Expectations, Lagos. PMG-MAN Publication.

Okubadejo, N., Ojo, O., Wahab, K., Abubakar, S.A., Obiabo, Y., Salawu, F., Ernest, N.,Agabi, O., Oshinaike, O (2018). A Nationwide Survey of Parkinson's Disease Medicines Availability and Affordability in Nigeria. Movement Disorders Clinical Practice 6 (1). DOI: 10.1002/mdc3.12682

Onalo, V.D, Danraka, A., Stephen, M.C. (2021). Quality Assessment of Some Brands of Levofloxacin 500mg Tablets Commercially Available in Gwagwalada, Abuja Scholars Academic Journal of Pharmacy (Sch Acad J Pharm) 10(3): 43-48 ISSN 2347-9531 (Print)| ISSN 2320-4206 (Online) Journal homepage: http://saspublishers.com DOI: 10.36347/sajp.2021.v10i03.002

Oyebuchi Ogbonna Brian (2015) National Drug Distribution in Nigeria; Implications for the Goals of National Drug Policy. European Journal of Pharmaceutical and Medical Research 3(1):01-04

Pharmaceutical Manufacturers' Group of Manufacturers' Association of Nigeria PMG-MAN (2010) Annual Report Publication, Lagos.

Sun Q, Santoro M, Meng Q, Liu C, and Eggleston K.(2008). Pharmaceutical Policy in China. Health Affairs. 27(4):1042-1050. 
Taylor O. (2012) Effectiveness of National Drug Policies in the West African Region. West African Journal of Pharmacy. 23(2): 27-33.

Umenai T, Narula IS. (1999). Revolving Drug Funds: A Step Towards Health Security. Bulletin of WHO. 77(2): $167-71$

United Nations Industrial Development Organization UNIDO (2011). Pharmaceutical Sector Profile: Nigeria.

Uzochukwu Benjamin SC, Obinna E Onwujekwe, Cyril O Akpala (2002). Effect of the Bamalo-Initiative Drug Revolving Fund on Availability and Rational Use of Essential Drugs in Primary Healthcare Facilities in South East Nigeria. Health Policy and Planning. 17(4):378-383 Oxford University Press

World Bank. (2018). Macro Poverty Outlook: Sub-Saharan Africa. Pg 266-277.

World Health Organization and Health Action International. (2008). Measuring Medicine Prices, Availability, Affordability and Price Components. 2nd Edition.

World Health Organization. (2015). WHO Guideline on Country Pharmaceutical Pricing Policies. WHO Press, Geneva, Switzerland. 